\title{
How physicians perceive and utilize information from a teratogen information service: The Motherisk Program Adrienne Einarson*1, Andrew Park ${ }^{2}$ and Gideon Koren ${ }^{1}$
}

\author{
Address: ${ }^{1}$ The Motherisk Program, The Hospital for Sick Children Toronto, Canada and ${ }^{2}$ The University of Toronto Medical School, Toronto, \\ Canada \\ Email: Adrienne Einarson* - einarson@sickkids.ca; Andrew Park - ajwp79@hotmail.com; Gideon Koren - gkoren@sickkids.ca \\ * Corresponding author
}

Published: 05 April 2004

BMC Medical Education 2004, 4:6

This article is available from: http://www.biomedcentral.com/I472-6920/4/6

(C) 2004 Einarson et al; licensee BioMed Central Ltd. This is an Open Access article: verbatim copying and redistribution of this article are permitted in all media for any purpose, provided this notice is preserved along with the article's original URL.
Received: 28 October 2003

Accepted: 05 April 2004

\begin{abstract}
Background: Teratogen information services have been developed around the world to disseminate information regarding the safety of maternal exposures during pregnancy. The Motherisk Program in Toronto, Canada, fields thousands of these inquiries per year. Our primary objective was to evaluate the perception and utilization of information received from us by physicians. Our secondary objective was to examine their information seeking behavior, in particular regarding teratogen information.
\end{abstract}

Methods: A one page survey was sent to physicians who had called Motherisk for information concerning pregnancy exposures in the previous 30 days for three months. Among the questions that were asked were demographics, which included gender, years in practice, specialty, information resources, and how they utilized the information received from Motherisk.

Results: We received II $8 / 200$ completed questionnaires (59\% response rate). The mean age of the respondents was: $42 \pm 9$ years, mean years of practice was: $14 \pm 8$ years, males: $46(38 \%)$ and females $72(62 \%)$ and $95(80 \%)$ were family physicians. $56(48 \%)$ researched their question prior to calling Motherisk, 106(91\%) and passed on the information received to their patient verbatim. The top four resources for information were: I) The CPS (PDR), 2) textbooks, 3) journals and 4) colleagues. Only $8 \%$ used the Medline for gathering information.

Conclusions: Physicians feel that a teratogen information service is an important component in the management of women exposed to drugs, chemicals, radiation and infections diseases etc. during pregnancy. Despite the advent of the electronic age, a minority of the physicians in our survey elected to use electronic means to seek information.

\section{Background}

Subsequent to the thalidomide tragedy, teratogen information services were developed in response to the public and health professionals need for evidence-based information regarding the safety/risk of exposures to drugs, chemicals, radiation and infectious diseases etc, during pregnancy and lactation. The vast majority of these services are telephone information lines, with a minority who see the women in a clinic setting [1]. Because of the paucity of this type of information, several of the centers, 
often in collaboration with other services around the world, also began to carry out outcome studies on the safety/risk of various exposures, which have been and continue to be published in peer reviewed journals. Over the years as a group, they have also sought ways of improving how this research is carried out [2]. This collaborative research has added substantially to the evidence based information, culminating over the years in a relatively large body of research in this field, which in turn can be transferred to the women and their health care providers [3-12].

The Motherisk Program is a teratogen information service that has been operating at The Hospital for Sick Children in Toronto, Canada since 1985. Over the years there has been a steady increase in the number of calls to our service per year, with 31,000 in 2002. Adding to this number of documented calls, there are approximately 12,000 callers per year who listen to our recorded information and do not patch through to a counselor, thus bringing up the overall total number of calls the service receives to approximately 43,000 calls per year. We also see between 450500 women per year in our clinic, where a letter is sent to her attending physician following her visit, documenting the evidence based information that was given to her regarding her exposure and any other reproductive risks.

Approximately 3000 of the telephone calls a year are directly from physicians. However, $90 \%$ of all the callers have been referred to our line by their physicians, as our service is very well known in Toronto and surrounding areas, as well as a substantial number of calls from the rest of Canada and the US. We have heard from many of our callers that it is standard practice during a pregnant women's first visit to her physician after confirmation of pregnancy, to be given Motherisk's phone number in case she has any questions regarding exposures during pregnancy.

The physicians who call us, have told us that they had heard about us mostly from word of mouth from their colleagues or quite frequently from having read the reviews which are published monthly in The Canadian Family Physician journal as "The Motherisk Update". These reviews evolve from actual questions asked by physicians using our fax service. Recently we published a history of our questions and answers and found that the most common questions physicians ask are in order of frequency: 1) antidepressants, 2) anti-epileptics, 3) antihistamines [13]. The physicians that call us on the telephone do not receive written information as time constraints do not allow, however if they request documentation, they are referred to our fax service. Most appear to be satisfied with the information they receive over the telephone, because it is rare that there is a request for written information following a telephone call.

There is a relative lack of published research in the literature examining physicians information seeking behavior in general and in particular reproductive toxicology. Studies carried out in the US, Canada, Norway, Australia and Switzerland, found that little had changed in physician information seeking behavior over the years despite the increased access to medical information. In all studied countries, use of electronic means to seek information was low and most physicians relied heavily on word of mouth from their colleagues, their own experience, drug product monographs, textbooks and journals [14-18].

Over the years we have delivered information to thousands of physicians via the telephone, but have never followed up to assess how they perceive the information received, or in turn how they use this information to counsel their pregnant patients. Our objectives were to assess utilization of information received, as well as information seeking behavior, in particular teratogen information.

\section{Methods}

The Motherisk Program has been participating in a course for medical students for the past ten years, run by the University of Toronto Medical School entitled "Determinants of Health in the Community" which aims to teach $2^{\text {nd }}$ year medical students about the inter-relationships between health issues and social determinants of health, which involves working with community agencies. The 20022003 student, developed a one page questionnaire, (see additional file 1) which was faxed to the physicians. The form consisted of 12 questions which could be filled out in less than 5 minutes following pilot testing. The first 6 questions dealt with demographics, such as age, gender, speciality, length of practice and numbers of pregnant women seen each year. The next 3 questions asked about information seeking behaviour. We listed eight resources to choose from: medline (PUBMED), colleagues, drug companies, textbooks, peer reviewed journals, media, Compendium of Pharmaceuticals and Specialties (CPS), which is the Canadian equivalent to the Physicians Desk Reference (PDI) in the USA and patients. They were then asked to rank in order their most frequently used resources. The latter part of the questionnaire asked several questions pertaining to the information that was received from Motherisk and how it was perceived by them in terms of clinical importance. At the end of the questionnaire, two lines were left empty and in this space participants were invited to make any additional comments. We chose to use a convenience sample of physicians who had called Motherisk requesting information in December 2002, January and February 2003. They were 
faxed the questionnaire within 1-2 weeks after their telephone call to Motherisk. To improve the response rate, the physician was sent a reminder fax 1 week after the first one.

Descriptive statistics in numbers and percentages were used to describe results.

\section{Results}

200 questionnaires were sent out to physicians who had called the program over a three month period and 118 were returned, with a response rate of $59 \%$. They originated from all over Canada, with 46 from Toronto and surrounding areas, 38 from other parts of Ontario and the remaining 34 distributed throughout the rest of the country from all provinces. The demographics of the physicians are described in (Table 1). Most of the respondents (91\%) passed on the information to their patients verbatim, despite the fact that almost half had researched the question prior to calling Motherisk. 12 of the respondents reported that they suggested a lower dose of the drug they prescribed to their pregnant patients and most of them reported the information they received was not different than they had expected. The top four sources for information were 1) The CPS, (PDR), 2) textbooks, 3) journals, 4) colleagues. (Table 2 ) Only $8 \%$ described the medline as being their number one source of information.

Table I: Demographics of respondents $N=1$ I 8

\begin{tabular}{ll}
\hline Age: mean \pm SD & $42 \pm 9$ years \\
Gender & female $=62 \%$ male $=38 \%$ \\
Specialty & family physicians $=80 \%$ \\
& OBS/Gynecology $=9 \%$ \\
& other II\% \\
Years of practice: mean \pm SD & $14 \pm 9$ years
\end{tabular}

Table 2: Perception and utilization of information $\mathrm{N}=\mid \mathrm{I} 8$

\begin{tabular}{ll}
\hline Question & $\%$ \\
\hline Research prior to calling Motherisk & 48 \\
Was information sufficient & 100 \\
Was information passed on verbatim to patient & 91 \\
Was information different than expected & 6 \\
Did you lower dose of drug & 10 \\
\hline
\end{tabular}

Most of the physicians (89\%) made comments at the bottom of the questionnaire, saying the services of Motherisk was very valuable to them and how they routinely pass on the telephone number to their patients. Several men- tioned that the information from Motherisk is documented in the patient's chart as "information given to patient as per Motherisk".

\section{Discussion}

To our knowledge, this is the first study of its kind to evaluate physicians perceptions and utilization of information received from a teratogen information service.

There were several interesting findings. Half of the respondents described researching their question first and almost all described the information not different than they expected. These findings lead us to believe that this group of physicians are perhaps not necessarily calling Motherisk for new information, but rather for reassurance. This confirms the findings of a study published where the authors found that physicians consult on average at least 3 sources before adopting a practice [19].

The finding of the $10 \%$ who advised their patient to lower the dosage of the drug, reflect a trend to lower drug dosage, often to ineffective levels during pregnancy, which we have found in other studies we carried out regarding antidepressant use during pregnancy. We never advise physicians to lower the dosage of a particular drug, we have found that they counsel their patients due to fears of teratogenicity and feel if the dose is reduced this may lower the teratogenic risk $[20,21]$.

The findings regarding physicians information seeking behavior, also confirmed the results in other studies examining such behavior. Previous researchers found that while more than $90 \%$ of physicians owned a computer, less than $10 \%$ were using them to access Medline [14-18]. We were aware that physicians were not using this service, because often women who call us will tell us that they called their physician prior to contacting Motherisk and was told that there was no information on the safety of a particular drug in pregnancy. Later the counselor would find a published study on the Medline and we would have to assume that the physician did not attempt to look up the information.

It was also interesting to note that far more female physicians called us than males; $62 \%$ versus $38 \%$. It is difficult to explain why this was so, one of the reasons (we have been told this by our callers), could be that more women today choose a physician that is female, so consequently more females would be the attending physician when a woman becomes pregnant.

There are several limitations to this study, mainly the sample size is small and our response rate was not extremely high (59\%). It could be that the physicians who did not return the questionnaire or who do not call Motherisk for 
Table 3: Information seeking behavior $\mathbf{N}=\mathbf{8 4}$ *

\begin{tabular}{lc}
\hline Rank order of resources (top four) & $\%$ \\
\hline I. CPS(US/PDI) & 23 \\
2. Peer reviewed journals & 22 \\
3. Textbooks & 16 \\
4. Colleagues & 10
\end{tabular}

* not all the physicians completed this section as requested

information may be very different from the respondents. They may be the ones who are consulting electronic means for information and feel comfortable with the information they have in counseling pregnant women on exposures in pregnancy. Another limitation, is that this survey was completed by physicians who were inquiring about teratogen information and the results may not be applicable to physician information seeking behaviors in general.

In summary, the results of our survey furnished us with information that allows us to better understand how physicians perceive this type of service and how they transfer the information to their pregnant patients. It was reassuring to know that physicians respect and trust the data that is given to them by a teratogen information service, which was evidenced by most of them passing on the information verbatim to their pregnant patients.

\section{Competing interests}

None declared.

\section{Authors' contributions}

$\mathrm{AE}$ conceived, designed the study and wrote the manuscript. AP participated in the design and carrying out of the study. GK participated in the design and writing of the manuscript. All authors have read and approved of the final manuscript.

\section{Additional material}

\section{Additional File 1}

Click here for file

[http://www.biomedcentral.com/content/supplementary/14726920-4-6-S1.doc]

\section{References}

I. Leen-Mitchell M, Martinez L, Gallegos S, Robertson J, Carey JC: Minireview: A history of organized teratology information services in North America. Teratology 2000, 6 I (4):314-7.

2. Chambers CD, Braddock SR, Briggs GG, Einarson A, Johnson YR, Miller RK, Polifka JE, Robinson LK, Stepanuk K, Lyons Jones K: Post- marketing surveillance for human teratogenicity: a model approach. Teratology 200I, 64(5):252-6I.

3. Einarson A, Shuhaiber S, Koren G: Effects of antibacterials on the unborn child: what is known and how should this influence prescribing. Paediatr Drugs 200I, 3(I I):803-I6.

4. Jones KL, Johnson KA, Dick LM, Felix RJ, Kao KK, Chambers CD Pregnancy outcomes after first trimester exposure to phentermine/fenfluramine. Teratology 2002, 65(3): I25-30.

5. Loebstein R, Addis A, Ho E, Andreou R, Sage S, Donnenfeld AE, Schick B, Bonati M, Moretti M, Lalkin A, Pastuszak A, Koren G: Pregnancy outcomefollowing gestational exposure to fluoroquinolones: a multicenter, prospective controlled study. Antimicrob Agents Chemother 1998, 42(6): I336-9.

6. Kulin NA, Pastuszak A, Sage SR, Schick-Boschetto B, Spivey G, Feldkamp M, Ormond K, Matsui D, Stein-Schechman AK, Cook L, Brochu J, Rieder M, Koren G: Pregnancy outcome following maternal use of the new selective serotonin reuptake inhibitors: a prospective controlled multicenter study. JAMA 1998, 279(8):609-10.

7. Einarson A, Fatoye B, Sarkar M, Lavigne SV, Brochu J Chambers C Mastroiacovo P, Mastroiacovo P, Addis A, Matsui D, Schuler L, Einarson TR, Koren G: Pregnancy outcome following gestational exposure to venlafaxine: a multicenter prospective controlled study. Am J Psychiatry 200I, I 58(10): I728-30.

8. Bailey B, Addis A, Lee A, Sanghvi K, Mastroiacovo P, Mazzone T, Bonati M, Paolini C, Garbis H, Val T, De Souza CF, Matsui D, Schechtman AS, Conover B, Lau M, Koren G: Cisapride use during human pregnancy: a prospective, controlled multicenter study. Dig Dis Sci 1997, 42(9): 1848-52.

9. Magee LA, Schick B, Donnenfeld AE, Sage SR, Conover B, Cook L, McElhatton PR, Schmidt MA, Koren G: The safety of calcium channel blockers in human pregnancy: a prospective, multicenter cohort study. Am J Obstet Gynecol 1996, 174(3):823-8.

10. Koren G, Pastuszak A, Ito S: Drugs in pregnancy. N Engl J Med 1998, 338(16): I I28-37.

II. Shuhaiber S, Einarson A, Radde IC, Sarkar M, Koren G: A prospective-controlled study of pregnant veterinary staff exposed to inhaled anesthetics and x- rays. Int J Occup Med Environ Health 2002, I 5(4):363-73.

12. Pastuszak AL, Levy M, Schick B, Zuber C, Feldkamp M, Gladstone J, Bar-Levy F, Jackson E, Donnenfeld A, Meschino W et al.: Outcome after maternal varicella infection in the first 20 weeks of pregnancy. N Engl J Med I 994, 330( I3):90I-905.

13. Einarson A, Portnoi G, Koren G: Update on motherisk updates. Seven years of questions and answers. Can Fam Physician 2002, 48: $130 \mid-4$.

14. Gorman P: Information needs in primary care: a survey of rural and non rural primary care physicians. Medinfo 200I, I0(Pt I):338-42.

15. Grimshaw JM, Eccles MP, Walker AE, Thomas RE: Changing physicians'behavior: what works and thoughts on getting more things to work. J Contin Educ Health Prof 2002, 22(4):237-43.

16. Forsetlund L, Talseth KO, Bradley P, Nordheim L, Bjorndal A: Many aslip between cup and lip. Process evaluation of a program to promote and support evidence-based public health practice. Eval Rev 2003, 27(2): 179-209.

17. Askew DA, Clavarino AM, Glasziou PP, Del Mar CB: General practice research: attitudes and involvement of Queensland general practitioners. Med J Aust 2002, I77(2):74-7.

18. Koller M, Grutter R, Peltenburg M, Fischer JE, Steurer J: Use of the Internet by medical doctors in Switzerland. Swiss Med Wkly 200I, I 3 I (I7-18):25I-4

19. Lockyer J, Jennett P, Parboosingh J, Maes W: Raising questions in clinical practice. J Contin Educ Health Prof I 988, 8(I):2। -6.

20. Jasper JD, Miropolsky Vlad, Varma Bindiya, Einarson Adrienne: Determinants of physician prescribing and non-prescribing of antidepressant medication during pregnancy. (Abstract) OTIS meeting June 2002, Scottsdale, Arizona, USA .

21. Bonari L, Einarson A, Jasper JD, Einarson TR, Koren G: Determinants of women's decision making, regarding the use of antidepressants during pregnancy. (Abstract) The North American Society for Psychosocial Obstetrics and Gynecology. 3/st Annual meeting, February 19th-22nd 2003, Lihue, Hawaii . 


\section{Pre-publication history}

The pre-publication history for this paper can be accessed here:

http://www.biomedcentral.com/1472-6920/4/6/prepub

Publish with Bio Med Central and every scientist can read your work free of charge

"BioMed Central will be the most significant development for disseminating the results of biomedical research in our lifetime. " Sir Paul Nurse, Cancer Research UK

Your research papers will be:

- available free of charge to the entire biomedical community

- peer reviewed and published immediately upon acceptance

- cited in PubMed and archived on PubMed Central

- yours - you keep the copyright 